\title{
The Associations between University Adjustment, Adult Attachment Styles, Personality Traits, and Perceived Stress
}

\author{
Ayşe Iraz Kural \\ $\mathrm{PhD}$ Student \\ Eötvös Loránd University \\ Doctoral School of Psychology and Education \\ Department of Psychology \\ Budapest, Hungary \\ Dr. Berrin Eylen Özyurt \\ Asst. Professor \\ Yaşar University \\ Faculty of Human and Social Sciences \\ Department of Psychology \\ İzmir, Turkey
}

\begin{abstract}
Transition to university is assumed to be closely related to individual variables such as; attachment, personality and stress perception patterns. This study examined how freshmen adjust university as a function of their attachment style, personality and stress perception patterns. The authors' aim was to investigate the relations between individual variables (personality, attachment style and perceived stress) and university adjustment success. A group of 277 freshmen from a University in İzmir completed the Experiences in Close Relationships Inventory, Perceived Stress Scale, Adaptation to University Life Inventory, Relationship Questionnaire, and Basic Personality Traits Inventory. Freshmen's attachment security was positively related to overall university adjustment, extraversion and openness to experience whereas negatively related to neuroticism, negative valence and stress perception. Stress perception, attachment anxiety and avoidance, extraversion and openness to experience were the significant predictors of university adjustment. Also, participants showed significant differences in attachment security, stress perception and university adjustment due to their demographic information. Research implications were discussed.
\end{abstract}

Keywords: attachment styles, personality traits, stress perception, collage adjustment

\section{Introduction}

The transition from high school to university is a major life change for many adolescents. Generally college life is associated with the process of 'strange situation' which is used to assess attachment behaviors in infancy as separation from caregivers in a novel environment, dealing with novel physical and social environments without older attachment figures while maintaining new social and romantic attachments (Kenny, 1987, 1990; Lapsey, Varshney, \&Aalsma, 2000; Rice, FitzGerald, Whaley, \& Gibbs, 1995).Beginning to university is one of the most stressful life events because of going to young adulthood, changing in family relations and perceived support from them, adapting to an entirely new environment. Learning how to be an independent adult, standing on their own feet, managing finances, and taking care of a variety of basic needs that parents used to do,are some developmental tasks of young adolescents need to cope (Baker, McNeil, \& Siryk, 1985; Fassig, 2001). Academic demands increase and new social relations are established (Tao et al., 2000). Students are often uncertain of their abilities to meet these demands (Dwyer \& Cummings, 2001).

Difficulties handling these stressors associated with the transition may lead to decreased academic performance and increased psychological distress (Dwyer \& Cummings, 2001). Although every student assumed to experience some stress during this transaction period, perceived level of stress shows differences from individual to 
individual. Personal appraisals of an event and types of resources for coping this event produces stress (Lazarus \& Folkman, 1987).

At this point, individual variables: personality types and attachment styles take the role and shape perceptions on stressors. Personality traits and attachment styles might be either protective or threatening for adjustment by shaping university related stress perception. The ability to adjust, blend in well, positively correlates with the attachment security (Mattanah, Hancock, \& Brand, 2004; Wintre \& Yaffe, 2000), higher levels of extroversion, agreeableness, and conscientiousness and relate with positive reappraisals and a better adjustment results (Quirk \&McCormick, 1998).

University adjustment is a multifaceted period, which consists of emotional adaptation, adaptation to college life, personal adaptation, adaptation to the relationships with opposite gender, academic adaptation, and social adaptation dimensions (Aladağ, Kağnıc1, Tuna, and Tezer, 2003). Academic adjustment simply indicates students' coping and achievement with the academic expectations of university. Also includes the efficiency of students' academic efforts, perceived acceptability of the academic environment and academic effort (Baker \&Siryk, 1984). Social adjustment includes relationships with friends, participation in social activities, and free time management, dealing with a new social environment effectively by establishing positive and accepting friendships and being involved in social activities on campus (Baker \& Siryk, 1986). Adjustment to opposite sex defined by safe and comfortable relationships with each gender and ability, motivation to form worthy romantic relationships whereas adjustment to the university environment might be regarded as the institutional adjustment, commitment to a particular university and sense of belongingness to the department and the university. Emotional adjustment includes well-being and emotional stability of the students during their first year at the university. Personal adjustment targets to rate self-confidence, self-approval, and self-esteem across various situations and places.

Stress is a subjective feeling that generally occurs when individual's behavior, physical status or cognitions are forced to change by an event/ situation. For Derogatis and Coons, (1993) stress is a byproduct of adaptation during a transition period. Beginning to university is a period that requires both adjustment and change at the same time. Stress was reported as the most common health factor, influencing students' academic adjustment by university students (American College Health Association, 2006). Increases in stress among freshmen predicted worse overall adjustment and low GPAs at the end of the academic year (Wintre \& Yaffe, 2000).Cognitive appraisals shape the behavior patterns when an individual comes across with a new environment/ situation (Lazarus, 1993). While perceived stress is one of these appraisals, students who perceive transition to university/a new environment more stressful, tend to adjust less since the impact of the stressful event is based on one's own perception of how stressful the event is (Cohen, Kamarck \& Mermelstein, 1983).

Generally college life is associated with the process of 'strange situation' which is used to assess attachment behaviors in infancy as separation from caregivers in a novel environment, dealing with novel physical and social environments without older attachment figures while maintaining new social and romantic attachments (Kenny, 1990; Lapsey, Varshney, \& Aalsma, 2000; Rice, FitzGerald, Whaley , \& Gibbs, 1995).It is suggested that young people must have a secure attachment style for them to adapt to the university transition period effectively (Blustein, Wallbridge, Friedlander \& Palladino, 1991). Because adults with a predominantly anxious attachment style experience more subjective stress than adults with a predominantly secure attachment style (Maunder, Lancee, Nolan, Hunter, \& Tannenbaum, 2006). Studying attachment style can be a predictor of the type of relationships, social and emotional processing styles that a person will form (Thompson \& Raikes,2003) when faced with a totally new situation/ environment. These styles can influence how one perceives and experiences stress (Collins\& Feeney, 2000; Feeney \& Collins, 2004). Studies on attachment and perceptions and expectations of stress and social support incorporate a theory-based prediction that insecure people are more likely to appraise others' responsiveness negatively (Mikulincer \& Shaver, 2009).

Wintre \& Yaffe (2000) indicated that students demonstrating low levels of fear of individuation or attachment are less likely to demonstrate negative emotions that could lead to better physical and psychological adjustment to college life. Another study being (Mattanah, Brand, \& Hancock, 2004) suggests that adolescents who have secure relationships have higher self-esteem and better emotional wellbeing which leads to easier and better adjustment process for the first year of college by increasing resilience. Securely attached students seek for and experience increased social support during the first two semesters of college, and this increased social support perception predicts improvements in social, emotional and personal adjustment, because increased perceived support results 
in a positive relation between attachment security and academic, social, emotional/ personal adjustment (Friedlander, Reid, Shupak, \& Cribbie, 2007).

Early experiences with attachment figures might be seen as a basis for various future abilities, such as social skills, emotion regulation capabilities, and exploratory behaviors (Sroufe, Egeland \& Kreutzer, 2005; Weinfield, Sroufe\& Egeland, 2008), and these aspects are linked to personality development. Bakker, Van Oudenhoven\& Van Der Zee, (2004) stated that attachment anxiety found moderately to strongly relate to neuroticism, whereas attachment avoidance negatively related to extraversion. Pamirand Arıkoğlu (2003) found that secure university students showed low attachment anxiety and avoidance, low distress, high self-restraint, high negative moodregulation.

Certain personality traits are found to be related with certain cognitions. Perceived stress is one of these cognitions, which are affected by personality. Personality moderates stress when processing and evaluating of the stress-provoking situation, coping strategies, and emotional consequences (Vollrath, 2001). When university students, freshmen, were studied to find the relationship between personality traits and perceived stress, extraversion was found to be negatively correlated with perceived university stress. They perceived university life less stressful. Contrary to extroverts, neurotics perceived this transition so 'threatening.' Neuroticism positively correlated with perceived stress (Lu, 1994). Penley and Tomaka (2002) studied Big Five personality types on stress and coping processes. Neuroticism was found to be high on perceived stress, and negatively correlated with perceived coping ability. Extraversion was low on perceived stress and positively correlated with perceived coping ability.

Little attention has been paid to how different personality traits (i.e., extroversion, neuroticism), attachment security (i.e., anxious, avoidant) and stress perception differentially associate with various facets of university adjustment. The present study examined the joint contribution of personality traits, attachment security and stress perception as predictors of adjustment to opposite gender, university environment, and academic, social, personal, emotional, overall adjustment. We were interested in (a) how different personality traits, and attachment security, and stress perception relate to adjustment and each other (b) the extent to which of eachfacet of adjustment and overall adjustment are significantly explained by these predictors (c) whether demographic features differ on adjustment and predictor variables or not in the present sample.

\section{Method}

\subsection{Participants}

277 freshmen students from a University located in İzmir attended to the study. All students ranged in age from 18 to 24 with a mean of $18.8(S D=1.12)$ and recruited from prep school. Of the total sample, $37.9 \%$ were male $(N=105)$ and $62.1 \%$ were female $(N=172)$. The $31 \%$ of the population were not from İzmir $(N=86)$, but study in İzmir; $58.5 \%$ of students $(N=162)$ said that they were satisfied with the number of friends, whereas $41.5 \%$ of them $(N=115)$ were not.

\subsection{Instruments}

In the present study, five instruments administered to the participants. (1) Experiences in Close Relationships Scale developed by Fraley, Waller and Brennan, (1998) and adapted to Turkish culture by Selçuk (2006). (2) Perceived Stress Scale developed by Cohen Kamarck and Mermelstein (1983), adapted by (Örücü and Demir, 2008) was used. (3) Adaptation to College Life Scale developed by Aladağ, Kağnıcı, Tuna, and Tezer (2003) was used. (4) Basic Personality Traits Inventory developed by Gençöz and Öncül (2012) was used for assessing the personality traits. It has 45 adjectives. (5) Relationship Scales Questionnaire (RSQ)developed by Griffin and Bartholomew (1994) and adapted by Sümer and Güngör (1999).

\subsection{Procedure}

Relevant permissions were gathered from the Ethical Committee of Yaşar University. A meeting was done with the head of Foreign Languages and different faculties to decide on application time/date. Preparatory School students and first year students were asked to voluntarily attend the study. An informed consent form wasprovided as the first page of the questionnaires and all the ones who accepted to participate were completed all the questionnaires which were re-created online via google forms. 


\section{Results}

Female students were rated as more anxiously attached, $F(1,275)=6.70, p<.05 ; \eta^{2}=.024$. In terms of university adjustment, one significant sex difference was found after Bonferroni correction was performed; female students showed less emotional adjustment, $F(1,275)=17.76, p<.05 ; \eta^{2}=.061$.

Female students significantly scored more on agreeableness, less on negative valence and openness to experience $\left[F(1,275)=9.15, p<.008 ; \eta^{2}=.032 ; F(1,275)=14.91, p<.001 ; \eta^{2}=.051 ;\right.$ respectively $]$. There were no significant sex differences on the remaining personality dimensions. Pearson correlation results revealed that all sub dimensions of university adjustment negatively correlate with all attachment dimensions and perceived stress. Thus, the more anxious and/ or avoidant an individual is, the less he /she is adapted to university. Students who perceive stress more tend to show worse adjustment patterns. When personality traits are considered all dimensions of university adjustment showed positive correlation with extraversion, conscientiousness, openness to experience and agreeableness, except that agreeableness was negatively correlated with emotional adjustment. On the other hand, negative valence and neuroticism traits showed negative relationship with all adjustment dimensions. Students show better adjustment if their neuroticism and negative valence scores are low and scores for remaining personality traits are high.

Table 1. Pearson Correlations Between Predictor Variables and University Adjustment

\begin{tabular}{lllllll}
\hline & A. A & S.A. & E.A. & P.A. & A.O. G & A.U. E \\
\hline Attachment Dimensions & & & & & & \\
Avoidance & $-.21^{* *}$ & $-.30^{* *}$ & $.20^{* *}$ & $-.33^{* *}$ & $-.59^{* *}$ & $-.40^{* *}$ \\
Anxiety & $-.25^{* *}$ & $-.40^{* *}$ & $.61^{* *}$ & $-.30^{* *}$ & $-.35^{* *}$ & $-.25^{* *}$ \\
Perceived Stress & $-.35^{* *}$ & $-.49^{* *}$ & $.61^{* *}$ & $-.39^{* *}$ & $-.30^{* *}$ & $-.40^{* *}$ \\
Personality Traits & & & & & & \\
Extroversion & $.30^{* *}$ & $.39^{* *}$ & .35 & $.32^{* *}$ & $.44^{* *}$ & $.40^{* *}$ \\
Neuroticism & $-.21^{* *}$ & $-.27^{* *}$ & $.37^{* *}$ & $-.16^{* *}$ & $-.15^{* *}$ & -.11 \\
Negative Valence & -.05 & $-.20^{* *}$ & -.07 & $-.13^{* *}$ & -.07 & $-.16^{* *}$ \\
Openness to Experience & $.24^{* *}$ &. $.32^{* *}$ & $.35^{* *}$ & $.56^{* *}$ & $.42^{* *}$ & $.37^{* *}$ \\
Conscientiousness & .06 & $.16^{* *}$ & .10 & $.22^{* *}$ & .09 & $.15^{*}$ \\
Agreeableness & .03 & $.21^{* *}$ & $-.13^{*}$ & $.23^{* *}$ & $.16^{* *}$ & $.22^{*}$
\end{tabular}

*p< $05, * * \mathrm{p}<.01$ SA: Social Adjustment, AOG: Adjustment to Opposite Gender, PA: Personal Adjustment, AA: Academic Adjustment, EA: Emotional Adjustment, AUE: Adjustment to University Environment.

Of the seven regression models that included all subdimensions of university adjustment scale in all models, perceived stress significantly related to adjustment. In terms of the regression models predicting adjustment from perceived stress, attachment dimensions and personality traits, the percentage of variance accounted for ranged from $64 \%$ (overall adjustment) to 20\% (academic adjustment). All predictor variables showed difference in their significance across the adjustment sub dimensions: (a) improved overall adjustment was predicted by decreased perceived stress $(\boldsymbol{\beta}=-.35)$, avoidance and anxiety $(\boldsymbol{\beta}=-24 ; \boldsymbol{\beta}=-.23$ respectively $)$ levels and increased extraversion $(\boldsymbol{\beta}=.18)$ and openness to experience $(\boldsymbol{\beta}=.20)$ significantly but not rest of the personality traits ; (b) Improved personal adjustment was predicted by decreased perceived stress $(\boldsymbol{\beta}=-.22)$, avoidance and anxiety $(\boldsymbol{\beta}=-12 ; \boldsymbol{\beta}=-$ .11 respectively)levels and increased agreeableness $(\boldsymbol{\beta}=.12)$ and openness to experience $(\boldsymbol{\beta}=.44)$ significantly but not rest of the personality traits; (c) Improved academic adjustment was predicted by decreased perceived stress $(\boldsymbol{\beta}=-.23)$, and increased extraversion $(\boldsymbol{\beta}=.17)$ significantly, but not by the rest of the personality traits and attachment dimensions; (d) Improved personal adjustment was predicted by decreased perceived stress $(\boldsymbol{\beta}=-.22)$, avoidance and anxiety $(=-12 ; \boldsymbol{\beta}=-.11$ respectively)levels and increased agreeableness $(\boldsymbol{\beta}=.12)$ and openness to experience $(\boldsymbol{\beta}=.44)$ significantly but not rest of the personality traits; (e) Improved social adjustment was predicted by decreased perceived stress $(\boldsymbol{\beta}=-.33)$, avoidance and anxiety $(\boldsymbol{\beta}=-.09 ; \boldsymbol{\beta}=-.21$ respectively $)$ levels and increased agreeableness $(\boldsymbol{\beta}=.18)$ and extraversion $(\boldsymbol{\beta}=.17)$ significantly but not rest of the personality traits; (f) Improved adjustment to opposite gender was predicted by decreased avoidance and anxiety $(\boldsymbol{\beta}=-.44 ; \boldsymbol{\beta}=-.25$ respectively)levels and increased extraversion $(\boldsymbol{\beta}=.16)$ and openness to experience $(\boldsymbol{\beta}=.12)$ significantly but not rest of the personality traits; $(\mathrm{g})$ Improved adjustment to university environment was predicted by decreased perceived stress $(\boldsymbol{\beta}=-.3)$, avoidance and anxiety $(\boldsymbol{\beta}=-22 ; \boldsymbol{\beta}=-.07$ respectively $)$ levels and increased openness to 
experience $(\boldsymbol{\beta}=.09)$ significantly but not by the rest of the personality traits; (h)Improved emotional adjustment was predicted by decreased perceived stress $(\boldsymbol{\beta}=-.34)$, anxiety $(\boldsymbol{\beta}=-.34)$, agreeableness and neuroticism $(=-.12$; $\boldsymbol{\beta}=-.09$, respectively)levels and increased extroversion $(\boldsymbol{\beta}=.11)$ and openness to experience $(\boldsymbol{\beta}=.14)$ significantly but not rest of the personality traits and avoidance dimension of attachment.

Table 2. Multiple Regressions Between Predictive and Adjustment Variables

\begin{tabular}{|c|c|c|c|c|}
\hline & $R^{2}$ & $B$ & $S E$ & $\beta$ \\
\hline Overall University Adjustment & .64 & & & \\
\hline Perceived Stress & & -1.77 & .21 & $-.35 * *$ \\
\hline Openness to Experience & & 1.78 & .38 & $.20 * *$ \\
\hline Avoidance & & -8.58 & 1.53 & $-.24 * *$ \\
\hline Anxiety & & -7.39 & 1.31 & $-.23 * *$ \\
\hline Extraversion & & 1.04 & .25 & $.18 * *$ \\
\hline Conscientiousness & & .40 & .23 & .08 \\
\hline Agreeableness & & .42 & .36 & .05 \\
\hline Neuroticism & & -.08 & .24 & -.01 \\
\hline Negative Valence & & -.14 & .50 & -.01 \\
\hline Personal Adjustment & .45 & & & \\
\hline Perceived Stress & & -.22 & .05 & $-.22 * *$ \\
\hline Openness to Experience & & .75 & .09 & $.44 * *$ \\
\hline Avoidance & & -.90 & .38 & $-.12 *$ \\
\hline Anxiety & & -.66 & .35 & $-.11 *$ \\
\hline Extraversion & & .04 & .06 & .04 \\
\hline Conscientiousness & & .09 & .06 & .08 \\
\hline Agreeableness & & .20 & .08 & $.12 *$ \\
\hline Neuroticism & & -.03 & .06 & -.03 \\
\hline Negative Valence & & -.11 & .12 & -.05 \\
\hline Academic Adjustment & .20 & & & \\
\hline Perceived Stress & & -.24 & .07 & $-.23^{*}$ \\
\hline Openness to Experience & & .12 & .12 & .06 \\
\hline Avoidance & & -.75 & .50 & -.09 \\
\hline Anxiety & & -.42 & .43 & -.06 \\
\hline Extraversion & & .21 & .08 & $.17 *$ \\
\hline Conscientiousness & & .03 & .07 & .02 \\
\hline Agreeableness & & .12 & .11 & .06 \\
\hline Neuroticism & & -.06 & .07 & -.05 \\
\hline Negative Valence & & -.04 & .15 & -.02 \\
\hline Social Adjustment & .42 & & & \\
\hline Perceived Stress & & -.26 & .04 & $-.33 *$ \\
\hline Openness to Experience & & .08 & .08 & .06 \\
\hline Avoidance & & -.58 & .32 & $-.09 * *$ \\
\hline Anxiety & & -1.01 & .28 & $-.21 *$ \\
\hline Extraversion & & .16 & .05 & $.17 *$ \\
\hline Conscientiousness & & .04 & .05 & .04 \\
\hline Agreeableness & & .24 & .07 & $.18^{*}$ \\
\hline Neuroticism & & -.02 & .05 & -.02 \\
\hline Negative Valence & & -.07 & .10 & -.03 \\
\hline Adjustment to Opposite Gender & .50 & & & \\
\hline Perceived Stress & & -.06 & .05 & -.07 \\
\hline Anxiety & & -1.42 & .30 & $-.25 * *$ \\
\hline Avoidance & & -3.13 & .35 & $-.44 * *$ \\
\hline Extraversion & & .17 & .05 & $.16^{*}$ \\
\hline Agreeableness & & .09 & .08 & .06 \\
\hline
\end{tabular}




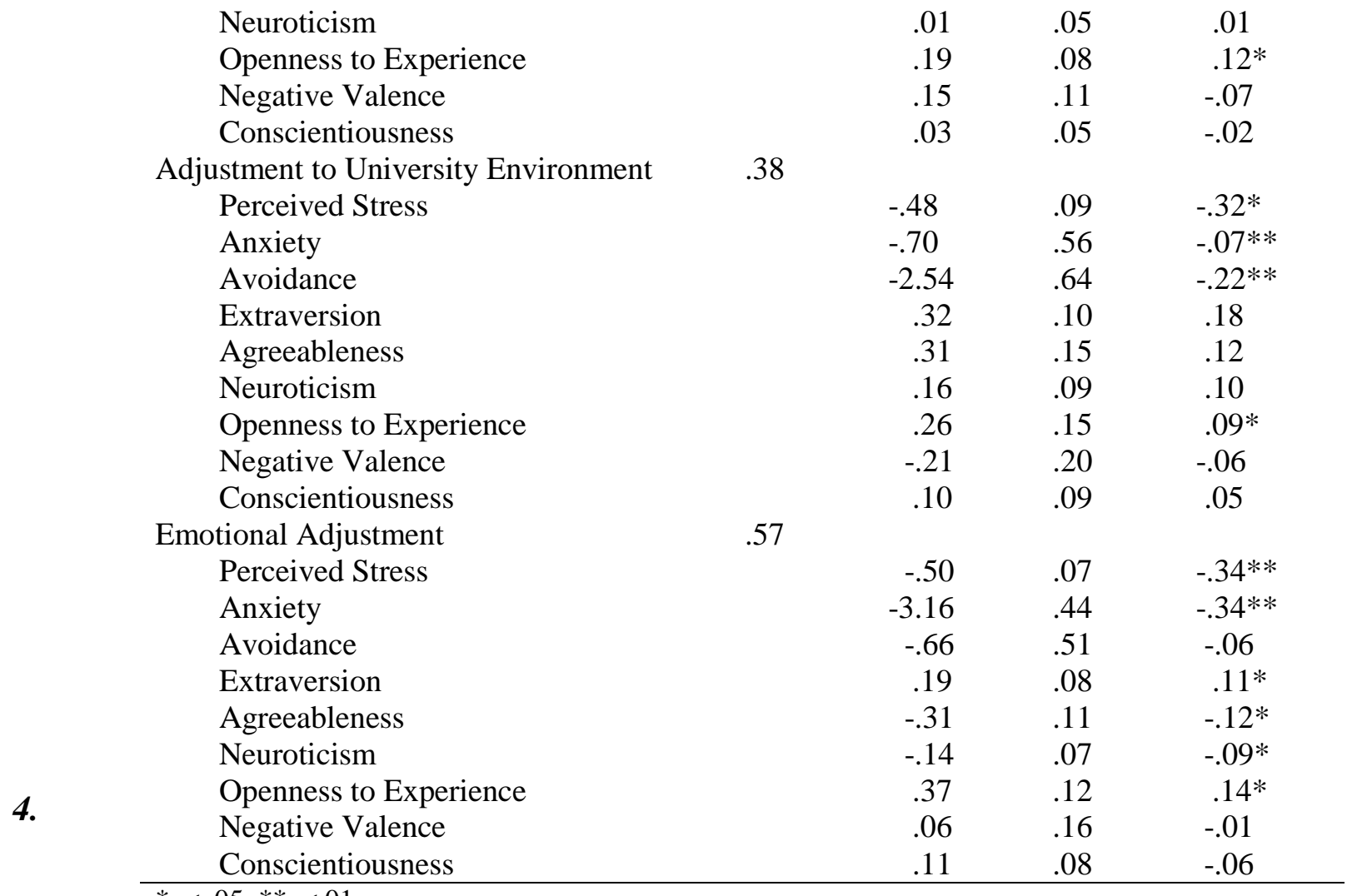

$* \mathrm{p}<.05, * * \mathrm{p}<.01$

\section{Discussion}

For attachment dimensions (anxiety and avoidance), statistically significant difference found only between gender groups with females showing higher anxiety levels than males. In Bartholomew and Horowitz's (1991) study, women showed preoccupied attachment style more while men showed dismissive attachment style. As preoccupied attachment style characterized by high attachment anxiety, the finding is consistent with ours. On the other hand, avoidance dimension did not differ across gender groups, which is not consistent with the finding that men mostly show dismissive attachment style. Western culture is used in attachment studies dominantly, and the difference between men and women regarding dismissive attachment might simply be the result of cultural diversity. Women who attended universities are most likely to aim to gain economic independence, which will make them perceive themselves stronger and equal to men. Eagly and Wood (1999) stated that when 'nurturer' role is not women's priority, the discrepancy between male and female psychology on relationships gets smaller. Therefore, women with more modern gender role perceptions might be as dismissive as men. Women who attend university might be from families where girls and boys treated equally without focusing on 'gender.' From an evolutionary point, university 'the stressful environment' might cause female students to show more dismissive tendencies (Belsky, 1991). Males and females show differences in all personality traits except extraversion and conscientiousness. Females showed higher levels of agreeableness whereas males showed higher levels of openness to experience, negative valence, and neuroticism. These findings were partly similar to the results of a study done by Burton, Hafetz, \& Henninger, (2007), through which women presented higher neuroticism and agreeableness, as well as higher extraversion than men were. In the present study, most of the male participants were the ones who left their hometown for University, this might be the reason for higher neuroticism levels. Female participants were likely to perceive their friendship number as sufficient which might lower their neuroticism levels and negative valence levels. Having enough number of friends would result in higher social support perception, which in turn provides higherwell-being, self-esteem, and emotional stability. Transition to university found to be harder for women, emotionally (Fisher \& Hood, 1987; Gall, Evans, \& Bellerose, 2000). Adaptation to College Questionnaire, found that academic adjustment did not differ across gender groups. 
Participants from İzmir showed a higher level of adjustment to the university environment, which is generally characterized by feeling familiar with the dominant culture/ norms/world view of the university than participants who attended the university from other cities. They also showed higher levels of personal adjustment, which mainly consists of a positive view of self. Good support networks foster adjustment (Hays \& Oxley, 1986).

Since students rely more heavily on school peers than parents during their first year in University (Tao, Dong, Pratt, Hunsberger, \& Pancer, 2000) and students who attend to university from another city spend most of their times to form new social networks (Paul \& Brier, 2001; Hays \& Oxley, 1986) these results were acceptable. Homesickness is not an issue for them, which would affect the emotional well-being of a student and be the reason why student from other towns showed worse personal adjustment.On the contrary, only personal adjustment differed across familial income groups: high-income levels associated with high adaptation levels. Economic stress might affect well-being of a student and might result in worse personal adaptation. Students who thought they have enough number of friends were more extrovertthan their counterparts. Extravert individuals showed high adjustment as they experience more positive affect in social situations (Denissen \& Penke, 2008; Elphick, Halverson, \& Marszal-Wisniewska, 1998; Fleeson, Malanos, \& Achille, 2002;) and this rewarding effect of the social interactions makes them to have more friends and peer acceptance (Scholte, Van Aken, \& Van Lieshout, 1997).Finding a negative relationship between negative valence and personal adjustment are in accordance with the expectations, students who have less self-esteem and negative self-view might find it hard to adjust personally within this new environment and their perceptions of incapability would increase resulting in less favorable opinions about self.

Perceived Stress differed across gender groups, perceived friendship number sufficiency, and attachment groups. Female students, students who thought they do not have enough number of friends and students with insecure attachment styles (preoccupied, fearful and dismissive) presented higher levels of perceived stress than their counterparts did. Matud (2004) found that females had higher levels of daily and chronic stress although they experience fewer life events when compared to males within last two years. Students might experience the transition to university either as very stressful or very easy regarding their personal resources, which includea number of social relations/ friends and closely relate with perceived social support (McDougall \& Hymel, 1998). As a result, perceived friendship sufficiency affects perceived social support, which associates with perceived stress significantly. Therefore, the less the support is, the more the perceived stress would be. Relying on others' support and feeling comfortable with asking help is not a characteristic of insecurely attached individuals, this would make them have higher stress levels.

When attachment took into consideration, openness to experience and extraversion were higher for the secure group and neuroticism was greater for the insecure groups. Anxiety and Avoidance dimensions of the attachment were found positively correlated with negative valence and neuroticism, whereas they all negatively correlated with the remaining personality traits. Securely attached individuals are more willing to explore their environment and find themselves in new situations (Cassidy \& Berlin, 1994), so they were accepted to be more extrovert and open to experience at the beginning of the present study. Regarding insecure attachment styles, preoccupied individuals had higher scores for agreeableness and negative valence. For individuals with preoccupied attachment style being approved by others is the most important thing (Bartholomew \& Horowitz, 1991), and negative self-view is an obvious characteristic of this attachment style (Cassidy, 2001). As agreeableness is crucial for fitting in a group, and negative view of self is a common point with negative valence, obtained results from the present study are in fact the expected findings when before mentioned features of preoccupied attachment style is considered. Fearful individuals had the highest neuroticism scores. Neurotic individuals tend to have more negative affectivity, which make them have negative views for their environment and as fearful attachment style is characterized by having a negativeview of others, less social relationships and support. In general, the view of self and others might be the basis for positive and high correlations between anxiety/ avoidance and neuroticism/negative valence. Beingfreshmen, in fact, might be handled as a strange situation experience; securely attached individuals show excitement and exploration behaviors rather than anxious and avoidant behaviors during their first year of university. It is also knownthat their self-evaluations are positive, and they have high self-esteem, which is a key factor for personal and social adjustment within university environment. Low interaction anxiety might indicate that students with secure attachment experienced 'leaving hometown' process more easily when leaving home to go to college (Mattanah et al., 2004). These might be the reason why securely attached individuals show better adjustment process. 
On the other hand, insecurely attached individuals perceive either themselves or others negatively. They have more negative perception of the university environment and less desire for developing new social bonds because of their insecurity. Anxiety led to fears of rejection, social skills deficits, and isolation (Wei, 2005) and these might result in worse adjustment process of the insecurely attached individuals within the present study.

Regarding perceived stress, anxiety and avoidance dimensions of attachment showed negative correlations with this variable. Adults who reported high levels of perceived stress also reported elevated levels of anxiety or avoidance. Securely attached individuals demonstrate more efficient participation in social structures when they are in need of help and have a tendency to use problem-focused strategies when they faced with stressful events(Ciechanowski, Sullivan, Jensen, Romano, \& Summers, 2003; Hunter \& Maunder, 2001; Mikulincer \& Florian, 1998). Participants with higher levels of neuroticism showed the greater levels of perceived stress. Neurotic individuals have high tendency to perceive most of the environmental stimulus as threatening and when faced with stressors they perceive even the daily situations as stressful compared to other personality traits (Schneider, 2004;Grant \& Fox , 2006; Lau, 2003; Matud, 2004). As expected, all university adjustment subscales negatively correlated with perceived stress, but emotional adjustment subscale showed highest correlation rate.

We also, looked at the predictive relationships between attachment, personality, perceived stress and university adjustment. All predictive variables explained $64 \%$ of the total university adjustment variance. Since life transitions generally triggered stress, beginning to university is expected to be predicted mostly by the perceived stress. Freshmen face with many new issues, like change in sleeping habits; vacations/breaks; change in eating habits; increased workload, new responsibilities, the workload required in college, competition among students, difficulty of the curriculum, homesickness, financial management, performance anxiety being approved, new social environment (Schneider, 2002; Saracoglu, Minden, \& Wilchesky, 1989; Abouserie, 1994; Johnson, Batia, \& Hauan, 2008).Freshmen also need to succeed many of these issues during an inadequateperiod of time. Extraversion by consisting of positive affect, assertiveness, and gregariousness might be useful for forming new friendships and passing peer acceptance challenges easily (Anderson, John, Keltner, \&Kring, 2001; Holahan, Valentiner, \& Moos, 1994). Furthermore, openness to experience causes thinking flexibility and high motivation/interest for new ideas, individuals, places, thoughts that might make adaptation to life transitions easier. Conscientiousness causes self-discipline and better personal organization. Both anxiety and avoidance dimensions of attachment predicted adjustment too, with avoidance showing more predictive variance than anxiety. Since avoidant individuals characterized by avoiding disappointment and they have a tendency to withdraw easily (Shi, 2003), creating new social bonds might take longer and might affect the adaptation period too. Tao and colleagues (2000) showed that perceived social support was related to academic, personal-emotional, and social adjustment during the $3^{\text {rd }}$ and $15^{\text {th }}$ weeks of the first semester which would be the reason why anxiety and avoidance dimensions of attachment predict worse adjustment levels, as they characterized by either being too close or away from others.Freshmen's adjustment was negatively predicted (Chroniak, 1998; Endler\& Parker, 1990; Heiman, 2004; Tuna, 2003) by avoidance coping strategies (Lazarus, 1993; Roth \& Cohen, 1986) which had the same pattern with the present findings.

All predictive variables explained $45 \%$ of the variance of personal adjustment. Only openness to experience, agreeableness, perceived stress, anxiety and avoidance dimensions of attachment were the significant predictors. Students with high openness to experience levels showed better personal adjustment as openness has the concept of a tendency to be intellectually and socially curious to new ideas, values,people, and environment. These individuals generally have high confidence rates, positive self-evaluations (Costa \& McCrae, 1992), which make them, fit better into a new social groups and positive self-evaluations with high self-esteem rates are the general features of personal adjustment. Locus of control and high self-esteem are main features of securely attached individuals (Bettencourt, Charlton, Eubanks, \& Kernahan, 1999; Njus \& Brockway, 1999; Sun \& Selış1k, 2009). These would help securely attached freshmen to cope with universitytransition which includes challenges and stress of meeting the personal demands of the new academic and social environment (Berzonsky \& Kuk, 2000; Chickering \& Reisser, 1993; D’Augelli \& Jay, 1991; Dyson \& Renk, 2006; Lau, 2003; Tuna, 2003) better in the present study. So, it is not surprising to find that low anxiety, avoidance, perceived stress and high openness to experience predict better personal adjustment.

Academic adjustment was significantly predicted by conscientiousness and perceived stress only. All predictive variables explained $20 \%$ of the variance. Previous research revealed that conscientiousness is the strongest predictor of academic adjustment (Propst, 2009). 
Students with high conscientiousness levels would havehigh academic motivation, characterized by being task oriented (Eysenck, 1991). Conscientiousness causes more responsibility feelings when compared to other personality traits, which would help students to be more insistent on their academic duties and study hard. Increases in stress among freshmen predicted worse academic adjustment in the present study. Stress interferes with academic achievement by lowering academic self-confidence, decreasing students' willingness to show academic effort and even causing dropouts (Wintre and Yaffe, 2000).

Regarding social adjustment, all predictive variables explained $42 \%$ of the variance. Perceived stress, avoidance and anxiety dimensions of attachment were the significant predictors. Low-stress perception predicted higher social adjustment for students in current study. This is because developing new friendships, forming pleasing interpersonal relationships on campus, and socially integrating into university life play a significant role in successful adjustment to university by decreasing negative expectations about university (Astin, 1993; Baker \& Siryk, 1984; Bonhert, Aikins, \& Edidin, 2007; Dextras, 1993; Freeman, Anderman, \& Jensen, 2007; Karahan, Sardoğan, Ozkamal1, \& Dicle, 2005; Langston \& Cantor, 1989; Lorang, Terenzini, \& Pascarella, 1981; Wise \& King, 2008). On the other hand, securely attached students showed better social adjustment. This would be because of maintaining a stable view of self and others across different situations as more securely attached individuals tend to have high levels of self-esteem that is the positive or negative attitudes toward oneself (Rosenberg, 1965) and elevated levels of personal worthiness (Coopersmith, 1967). Also, high self-esteem related to greater social adjustment in a number of studies (Geist \&Borecki, 1982; Rice, 1999). Similar to securely attached children exploring environment (Cassidy \& Berlin, 1994) and seeking care (Cassidy, 2001), secure students would seek out care and advance their capacities to form intimate relationships while being totally confident with themselves, unlike their avoidant and anxious counterparts.

Adjustment to opposite sex defined by safe and comfortable relationships with each gender and ability, motivation to form worthy romantic relationships were significantly predicted by avoidance and anxiety dimension of attachment, openness to experience and extraversion. All predictive variables clarified $50 \%$ of the variance. Low avoidance levels related with high adjustment by being more willing to form relationships and perceiving others more reliable while having more positive view of self. Low Anxiety levels predicted better adjustment pattern since it means having low dependence on others and having a stable view of self. Individuals who show high dependence in their relationships might fear others and even might make others stay away from these people. This is, in fact, the paradox of being highly anxious, not wanted by others while craving to form relationships with them. When traits are the concern, only extraversion and openness to experience indicated significant predictive power. Beyond all of the before-mentioned features of these traits, in the current study, relationship satisfaction might be the reason why these individuals show better adjustment. Because some of the previous studies have found that extroversion is a strong predictor of relationship satisfaction (Malouff 2010; White, 2004) Extroversion and Openness associated with greater satisfaction in relationships (Shiota \& Levenson, 2007).

Adjustment to the university environment, which might be regarded as the institutional adjustment, is affected by institutional identity and sense of belongingness to the department and the university. Perceived stress, anxiety and avoidance dimension of attachment and openness to experience were the significant predictors. All predictive variables explained 38\% of the variance for Adjustment to University Environment. Openness to experience and low perceived stress levels, anxiety and avoidance associated with better adjustment to university's rules, culture, way of teaching, etc.. Students with an avoidant attachment style would have the tendency to 'flight' when faced with a stressor about the university and might even drop-out as avoidance coping strategies that predicted the adjustment of first-year college students negatively (Chroniak, 1998; Endler \& Parker, 1990; Heiman, 2004; Tuna, 2003). High openness to experience provide individuals with greater satisfaction with their social relationships and might help them fit in an unfamiliar environment easily by providing great motivation to face with challenging circumstances, like forming new social relationships. This might be the reason why students with high levels of openness to experience, feel belonged to the university and their new social environment in the current study. Moreover, motivation brought satisfaction and enjoyment towards college life (Baker, 2004; Shankland, Genolini, Franc, Guel, \& Ionescu, 2010). Halamandaris and Power's (1999) study showed high satisfaction with the social and academic components of university life which was predicted by perceived social support is likely to be greater for the character traits listed above. 
Emotional adjustment significantly predicted by perceived stress, extraversion, openness to experience, neuroticism, agreeableness, avoidance and anxiety dimensions of attachment. All predictive variables explained $57 \%$ of the variance. Sinceemotional adjustment includes well-being of the students and stress affects physical and psychological health negatively, it is not surprising to find low perceived stress levels predicting better emotional adjustment in this current study. High extraversion, openness to experience, low agreeableness and neuroticism were related to better adjustment. Low levels of interpersonal problems and having a positive tendency and high motivation to deal with stressful life events, predictive features of students with high extroversion and openness to experience, resulted in higher emotional adjustment (Zuckerman, 1998).

On the contrary, high neuroticism levels might lead to distortions in perception of social cues and less satisfaction of life and as the leading factor for worse outcomes during critical life transitions (McCrae \& Costa, 1996). The finding that high neuroticism is related with worse adjustment is completely in accordance with the earlier studies. Surprisingly, agreeableness, a character trait characterizedby providing harmony within relationships, showed a negativecorrelation with emotional adjustment. The reason why agreeableness showed such an interesting association might be because of trying to fit in too much without giving attention to personal needs as this has been found to help students get along and avoid conflicts with roommates and classmates (Graziano, JensenCampbell, \& Hair, 1996). Discontent for personal needs, focusing only on others' desires and pretending to be someone else, might be the reason why individuals with high agreeableness displayed low emotional adjustment.

Only self-reported measures were used, this might have caused socially desirable responses. On the other hand, response bias is another problem for attachment scales. Stress, Attachment styles, and personality were modeled as predictors of adjustment however; some studies modeled psychological (emotional) adjustment as one predictor of stress among college students (Dusselier, Dunn, Wang, Shelley, \&Whalen, 2005). Consistent and significant relations between perceived stress and all aspects of university adjustment shows that a particular importance must be on stress management courses to help student deal with the university demands. Easily accessible sports and recreational facilities in university environment may help students exercise more regularly as one method of modulating stress (Campbell, Svenson, \& Jarvis, 1992). Since secure attachment results in greater adjustment among freshmen and it is a protective factor against the stressful demands of university life, features of secure attachment should be encouraged, practiced and maintained.

\section{References}

Abouserie, R. (1994). Sources and levels of stress in relation to locus of control and self-esteem in college students. Educational Psychology: An International Journal of Experimental Educational Psychology, 14 (3), 323-330.

Anderson, C., John, O. P., Keltner, D., \&Kring, A. M. (2001). Who attains social status? Effects of personality and physical attractiveness in social groups. Journal of Personality and Social Psychology, 81, 116-132.

Astin, A. W. (1993). What matters in college? Four critical years revisited. SanFrancisco: Jossey-Bass Publishers.

Berzonsky, M. D., \& Kuk, L. S. (2000). Identity status, identity-processing style and the transition to university. Journal of Adolescent Research, 15, 81-98.

Bettencourt, B. A., Charlton, K., Eubanks, J., \&Kernahan, C. (1999). Development of collective self- esteem among students: Predicting adjustment to college. Basic and Applied Social Psychology, 21(3), 213-222.

Bonhert, A. M., Aikins, J. W., \&Edidin, J. (2007). The role of organized activities in facilitating social adaptation across transition to college. Journal of Adolescent Research, 22(2), 189-208.

Cassidy, J., \& Berlin, L. J. (1994). The insecure/ambivalent pattern of attachment: Theory and research. Child Development, 65, 971-981.

Cassidy, J. (2001). Truth, lies, and intimacy: An attachment perspective. Attachment and Human Development, 3, 121155.

Chroniak, K. R. (1998). Coping and adjustment in the freshman year transition (Doctoral dissertation, Northwestern University). Retrieved from http://www. worldcat.org/

Ciechanowski, P. Sullivan, M., Jensen, M., Romano, J., Summers, H. (2003). The relationship of attachment style to depression, catastrophizing and health care utilization in patients with chronic pain. Pain. 104(3):627-637.

Collins, N. L., \& Feeney, B. C. (2004). Working models of attachment shape perceptions of social support: Evidence from experimental and observational studies. Journal of Personality and Social Psychology, 87, 363-383

D’Augelli, A. R., \& Jay, G. M. (1991). Social support and adjustment to university life: A comparison of African American and white freshman. Journal of Community Psychology, 19, 95-108. 
Dwyer, A. L. \& Cummings, A. L. (2001). Stress, self-efficacy, social support, and coping strategies in university students. Canadian Journal of Counseling, 35(3), 208-220.

Dyson, R., \&Renk, K. (2006). Freshmen adaptation to university life: Depressive symptoms, stress, and coping. Journal of Clinical Psychology, 62(10), 1231- 1244

Dextras, S. (1993). Freshmen perceptions of academic and social changes during the first year of college (Doctoral dissertation). Available from ProQuest Dissertations and Theses database. (UMI No. 9407239)

Endler, N. S., \& Parker, J. D. A. (1990). Multidimensional assessment of coping: A critical evaluation. Journal of Personality and Social Psychology, 58, 844- 854.

Eskin, M., Harlak, H., Demirkiran, F. veDereboy, Ç. (2013). Algılanan Stres Ölçeğinin Türkçeye Uyarlanması: Güvenirlik ve Geçerlik Analizi. Yeni Sempozyum, 51(3), 12-20.

Eysenck, H.J. (1991). Dimensions of personality: 16, 5, or 3? Criteria for a taxonomic paradigm. Personality and Individual Differences, 12, 773-790

Fassig, E. I. (2003). Attachment and resilience as predictors of adjustment to college in collegefreshmen. (Doctoral dissertation). Available from ProOuestDissertations and Theses database. (UMI No. 3099706)

Fisher, S., \& Hood, B. (1987). The stress of the transition to university: A longitudinal study of psychological disturbance, absent-mindedness, and vulnerability to homesickness. The British Psychological Society, 78, 425-441.

Freeman, T. M., Anderman, L. H., \& Jensen, J. M. (2007). Sense of belonging in college freshmen at the classroom and campus levels. The Journal of Experimental Education, 75, 203-220.

Gall, T. L., Evans, D. R., \& Bellerose, S. (2000). Transition to first-year University: Patterns of change in adjustment across life domains and time. Journal of Social and Clinical Psychology, 19(4), 544-567.

Geist, C. R., \&Borecki, S. (1982). Social avoidance and distress as a predictor of perceived locus of control and level of self-esteem. Journal of Clinical Psychology, 38(3), 611-613.

Graziano, W. G., Jensen-Campbell, L. A., \& Hair, E. C. (1996). Perceiving interpersonal conflict and reacting to it: The case for agreeableness. Journal of Personality and Social Psychology, 70, 820-835.

Griffin, D. W. \& Bartholomew, K. (1994). The Metaphysics of measurement: The Case of adult attachment. Advances in Personal Relationships: Attachment Processes in Adulthood: Vol. 5 (pp. 17-52). London: Jessica Kingsley Publishers.

Hawkins, A.C., Howard, A., Oyebode, J. R. (2007). Stress and coping in hospice nursing staff. The impact of attachment styles. PscyhoOncology, 16(6), 563- 572.

Hays, R. B., \& Oxley, D. (1986). Social network development and functioning during a life transition, Journal of Personality and Social Psychology, 50(2),305-313.

Heiman, T. (2004). Teachers coping with changes: Including students with disabilities in mainstream classes: An international view. International Journal of Special Education, 19(2), 91-102.

Holahan, C.J, Valentiner, D.P., Moos, R.H. (1994). Parental support and psychological adjustment during the transition to young adulthood in a college sample. Journal of Family Psychology; 8: 215-223 doi:10.1037/08933200.8.2.215

Karahan,T.F.,Sardoğan,M.E.,Özkamalı,E, veDicle, A.N. (2005). ÜniversiteI. sınıföğrencilerininüniversiteyeuyumdüzeylerininsosyokültüreletkinlikleraçısındanincelenmesi. ÇukurovaÜniversitesiĔ̈itimFakültesiDergisi, 30, 63-72.

Kenny, M. E. (1987). The extent and function of parental attachment among first-year college students. Journal of Youth and Adolescence, 16, 17-27.

Kenny, M. E. (1990). College seniors' perceptions of parental attachments: The value and stability of family ties. Journal of College Student Development, 31, 39-46.

Langston, C., \& Cantor, N. (1989). Social anxiety and social constraint: When making friends is hard. Journal of Personality and Social Psychology, 56, 649-646.

Lapsley, D. K., Varshney, N., \&Aalsma, M. (2000). Psychological attachment and attachment style in late adolescence. Journal of Adolescence, 23, 137-155.

Lau, L. (2003). Institutional factors affecting student retention. Education, 124, 66-80.

Lazarus, R. (1993). From psychological stress to the emotions: A history of changing outlooks. Annual Review of Psychology, 44(1), 1-21.

Lorang, W. G., Terenzini, P. T., \& Pascarella, E. T. (1981). Predicting freshman persistence and voluntary dropout decisions: A replication. Research in Higher Education, 15(2), 109-127.

Malouff, J. M., Thorsteinsson, E. B., Schutte, N. S., Bhullar, N., \& Rooke, S. E. (2010). The Five-factor model of personality and relationship satisfaction of intimate partners: A meta-analysis. Journal of Research in Personality, 44,124-127. 
Marmarosh, C.L., Markin, R.D. (2007). Group and personal attachments: Two is better than one when predicting college adjustment. Group Dynamics: Theory, Research, and Practice, 11, 153 - 164.

Mattanah, J. F., Brand, B. L. \& Hancock, G. R. (2004). Parental Attachment, Separation-Individuation, and College Student Adjustment: A Structural Equation Analysis of Mediational Effects. Journal of Counseling Psychology, 31, 213-225.

Matud, P. (2004). Gender differences in stress and coping styles. Journal of Personality and Individual Differences, 37, 1401-1415.

McCrae, R. R., \& Costa, P. T., Jr. (1996). Toward a new generation of personality theories: Theoretical contexts for the Five-Factor Model. In J. S. Wiggins (Ed.), The Five-Factor Model of personality: Theoretical perspectives (pp.51-87). New York: Guilford Press.

McDougall, P., \& Hymel, S. (1998). Moving into middle school: Individual differences in the transition experience. Canadian Journal of Behavioural Science, 30(2), 108- 120.

Mikulincer, M., Florian, V. (1998). The relationship between adult attachment styles and emotional and cognitive reactions to stressful events. In: Simpson JA, Rholes WS (eds.) Attachment theory and close relationships. Guilford Press, New York, pp 143-165.

Njus, D. M., \& Brockway, J. H. (1999). Perceptions of competence and locus of control for positive and negative outcomes: predicting depression and adjustment to college. Personality and Individual Differences, 26(3), 531548.

Orucu, M.C., Demir, A.(2008). Psychometric evaluation of perceived stress scale for Turkish university students. Stress and Health, 25, 103-109.

Paul, E., \& Brier, S. (2001). Friend sickness in the transition to college: Pre-college predictors and college adjustment correlate. Journal of Counseling and Development. 79(1), 77-89

Poropat, A. E. (2009). A Meta-analysis of the Five-factor Model of Personality and Academic Performance. Psychology Bulletin 135: 322-338.

Quirk, S. W. \& McCormick, R. A. (1998). Relationships among personality subtypes of substance abusers, coping style, impulsivity, depressive symptoms, and patterns of substance choice. Assessment, 5, 157-169.

Rice, K. G., FitzGerald, D. P., Whaley, T. J., \& Gibbs, C. L. (1995). Cross-sectional and longitudinal examination of attachment, separation individuation, and college student adjustment. Journal of Counseling \& Development, $73,463-474$.

Roth, S., \& Cohen, L. (1986). Approach, avoidance and coping with stress. American Psychologists, 41, 813-819.

Saracoglu, B., Minden, H., \&Wilchesky, M. (1989). The adjustment of students with learning disabilities to university and its relationship to self-esteem and self-efficacy. Journal of Learning Disabilities, 22, 590-592.

Shi, L. (2003). The association between adult attachment styles and conflict resolution in romantic relationships. The American Journal of Family Therapy, 31, 143-157.

Shiota, M. N., \& Levenson, R. W. (2007). Birds of a feather don't always fly farthest: Similarity in big five personality predicts more negative marital satisfaction trajectories in long-term marriages. Psychology and Aging, 22,666 675.

Sümer, N., \& Güngör D. (1999). Yetişkin bağlanma stilleri ölçeklerinin Türk örneklemi üzerinde psikometrik değerlendirmesi ve kültürlerarası bir karşılaştırma. Türk Psikoloji Dergisi, 14, 71-106.

Tao, S., Dong, Q., Pratt, M. W., Hunsberger, B., \&Pancer, S. M. (2000). Social support: Relations to coping and adjustment during the transition to university in the People's Republic of China. Journal of Adolescent Research, 15(1), 123-144.

Wei, M., Vogel, D. L., Ku, T.-Y., \&Zakalik, R. A. (2005). Adult attachment, affect regulation, negative mood, and interpersonal problems: The mediating roles of emotional reactivity and emotional cutoff. Journal of Counseling Psychology, 52, $14-24$.

Wintre, G. M. \&Yaffe, M. (2000). First - year students' adjustment to university life as a function of relationships with parents. Journal of Adolescent Research, 15, 9 -37. 